\title{
RTK 技术在市政工程测量中的运用分析
}

\author{
刘玉强 \\ 北京慧智蓝图测绘有限公司 \\ DOI:10.32629/gmsm.v3i1.477
}

[摘 要] 市政工程是我国工程建设的重要组成部分,是与人们生活息息相关的民生工程建设。在市政工程开展中,工程测量工作是重要的工程 施工组成部分, 是工程施工开展的基础所在。随着近年来工程技术体系不断发展, 市政工程测量中先进技术的应用愈加普及,RTK技术就是现阶 段市政工程测量中应用的主要技术。本文对RTK技术分析,探究其在市政工程测量中应用时存在的不足之处,并研究市政工程测量中RTK技术 的运用策略。

[关键词] RTK技术; 市政工程测量；运用

\section{引言}

RTK技术是新时期GPS技术应用的最新技术成果, 是一种新型卫星定位 测量方法, 对市政工程测量工作的开展具有重大的推进意义, 能够有效提 升市政工程测量工作的效率和精准性, 为市政工程施工工作开展提供精准 的测量数据支撑 ${ }^{[1]}$ 。随着RTK技术在市政工程中应用逐渐得到肯定与认可, 对RTK技术在市政工程测量中科学化应用策略的探究已经成为了推动当前 市政工程测量工作作业效率提升的重要途径。

\section{RTK 技术概述}

RTK载波相位差分技术, 是一种实时动态性的工程测量技术体系, 是 GPS应用新时期最新发展, 对于工程测量技术体系发展有着里程碑式的意 义。RTK技术是通过对两个测量站之间的载波相位观测量进行实时处理与 分析的差分式工程测量方法, 通过对基准站所采集到的载波相位数据传输 给用户的接收装置, 然后通过对采集的载波相位数据进行求差结算坐标, 来实现对工程情况的测量, 是新时期较为常用的卫星定位测量方法, 对于 市政工程测量中的工程放样、地形测图有着重大的推动作用, 能够有效提 升市政工程测量工作的作业效率, 对于市政工程发展有着重要作用。

\section{RTK 技术在市政工程测量中的运用作用}

第一, RTK技术能够有效提升市政工程测量工作的效率。市政工程施工 开展中, 工程测量是工程施工开展的基础所在; 提升市政工程测量工作的 效率, 是提升市政工程整体施工下效率的重要途径。通过对RTK技术在市政 工程测量中的运用, 能够有效提升工程测量的效率, 提升整体市政工程施 工的作业效率, 是推动我国市政工程建设发展的重要途径。

第二, RTK技术能够有效提升市政工程测量工作的精准性。工程测量工 作的首要工作原则就是要保证市政工程测量的精准性, 才能够为市政工程 开展提供充足的测量数据支撑, 保证工程开展的科学性和质量。RTK技术在 市政工程测量中的应用, 能够为工程测量工作的精准性提供保障, 通过载 波相位差分的测量计算方式, 能够对测量数据进行精细化分析, 进而提升 工程测量结果的精准性, 保证市政工程施工科学化开展。

第三, RTK技术为市政工程测量的控制测量提供了新的测量原理和方 法。RTK技术是以载波相位差分技术为技术核心的工程测量方法, 对于GPS 应用有着重要的推进意义。在RTK技术运用在市政工程测量中时, 能够为市 政工程测量的工程放样、地形测图以及所涉及到的各种测量控制工作提供 新的测量原理支撑和测量方法支撑, 对于RTK技术的运用已经成为了提升 市政工程测量工作效率的必要举措。

\section{RTK 技术在市政工程测量运用中存在的不足}

虽然当前阶段大部分市政工程测量中都开始了RTK技术的运用, 为市 政工程测量工作的发展提供了技术支撑与保证, 大大推动了市政工程施工
发展, 但是在现阶段的市政工程测量RTK技术运用中, 仍然存在一定的运用 不足, 给市政工程测量工作的发展带来了不利影响 ${ }^{[2]}$ 。

第一, RTK技术在市政工程测量中运用时缺乏规范化的应用标准要求。 RTK技术作为新时期工程测量技术的重要体现, 在市政工程测量中进行RTK 技术应用时, 就需要对RTK技术的应用流程进行规范化、标准化要求, 以保 证RTK技术的应用质量。但是在现阶段的市政工程测量中, 对于RTK技术应 用还缺乏规范化的流程要求, 因此给RTK技术运用带来了不利影响。

第二, 部分市政施工单位在工程测量中对RTK技术运用的重视程度有 待提升。虽然RTK技术已经在大部分市政工程测量中得以应用, 并为市政工 程测量工作发展提供了支撑。但是部分市政工程施工单位对于RTK技术的 认知程度以及在市政工程测量中的应用仍然存在重视不足的情况, 这就给 RTK技术在市政工程测量中的应用带来了不利影响, 对于市政工程测量工 作的开展造成了不利冲击。

第三, 市政工程测量工作中运用RTK技术时存在专业技术人员缺乏 的现实问题。RTK技术作为新时期GPS应用的重要技术体系, 在市政工程 测量中进行RTK技术运用, 需要专业的技术工作人员进行操作, 才能够保 证RTK技术的功能性得到保障。但是现阶段还存在着RTK技术人才数量与 日益增长的市政工程项目数量不平衡的现实情况, 给市政工程测量中 RTK技术的运用带来了发展制约, 影响了市政工程测量中RTK技术的高质 量运用。

\section{RTK 技术在市政工程测量中的运用策略}

第一, 建立规范化的RTK技术运用流程。规范化的技术应用流程是保证 RTK技术在市政工程测量中运用时其技术功能得以完全发挥的必然途径, 因此在市政工程测量中进行RTK技术应用时, 工程施工单位要在专业RTK技 术人员的技术应用原则要求基础上, 建立规范化的RTK技术运用流程要求, 通过市政工程测量中RTK技术的标准化应用, 提升市政工程测量工作的效 率和精准度, 为市政工程施工的顺利开展提供保证。

第二, 加强对RTK技术的推广应用, 提升市政工程单位对RTK技术的认 知。市政工程施工单位对RTK技术的认知与了解直接决定了市政工程测量 中RTK技术运用的可能性和运用过程的标准性 ${ }^{\left[{ }^{3]}\right.}$ 。因此, 要想保证RTK技术 在市政工程测量中的运用质量, 就要提升市政工程施工单位对RTK技术体 系的认知。因此, 相关部分要加强对RTK技术的宣传与推广, 并组织相应的 技术推广会, 要求市政工程单位的负责人参加, 提升其对RTK技术的了解与 认知, 进而为市政工程测量中RTK技术的运用奠定基础。

第三, 落实技术人员培养机制, 为RTK技术在市政工程测量中的运用提 供人才支持。RTK技术作为新时期工程测量技术的重要体现, 在市政工程测 量中进行RTK技术运用时, 必须要通过专业技术人员的操作才能够保证RTK 


\title{
GPS 技术在测量工程中的应用及其精度控制
}

\author{
窦志云
}

辽宁省地矿测绘院有限责任公司

DOI:10.32629/gmsm.v3i1.530

[摘 要] 在现代化城市建设日益推进的大背景下,我国工程项目建设规模在不断扩大,很多先进技术在工程项目建设中得到了有效应用,GPS技 术作为一种新兴技术, 在工程测绘中发挥着重要作用,有利于提高工程测量的精确度,改善传统工程测量技术中数据不准确、人力和物力等资源 浪费的问题。因此,在工程测绘过程中,相关部门需要引进GPS技术,提高工程测绘的精确度,文章主要对GPS技术在测量工程中的应用及其精度 控制进行了研究。

[关键词] GPS技术; 测量工程; 应用; 精度控制

\section{引言}

在通信技术的快速发展中, GPS技术和通信技术进行了有效融合, 三 维坐标测定由传统的静态转变成了动态, 定位与导航逐渐成为实时测量, 无需利用数据处理获取, 在很大程度上扩展了GPS技术的广度和深度 ${ }^{[1]}$ 。现 阶段, GPS技术在很多工程项目测量中得到了广泛应用, 并对测量精度进 行了有效控制, 提高了测量数据的准确性。基于此, 文章介绍了GPS技术 在测量工程中的应用优势, 研究了GPS技术在测量工程中的应用及其精 度控制措施。

\section{GPS 技术在测量工程中的应用优势}

通常情况下, 工程测量的范围相对较小, 在实地测量过程中, 常用的设 备是经纬仪、全站仪和水准仪, 测量过程中各个点需要互动, 这就需要引进 GPS技术, 获取更多准确的测量数据, 减少方格网点的误差, 进一步提高图 形的准确性。同时, GPS测量建筑方格网时, 其工作效率提高了一倍以上, 降低了工作人员的劳动强度, 在一个参考站中由多台流动站作业, 无需基 准站指挥, 单人可以独立作业, 下文主要介绍了 GPS技术在工程测量中的应 用优势。

1. 1 快速定位

GPS技术作为一种先进技术, 各项配置都比较完善, 在定位过程中常用 的模式是实时动态定位模式, 其能够实时定位, 提供三维坐标, 提高了测量 工作的整体效率。另外, 各个观测站无需通视, 选点具有一定的灵活性, 但 需要注重观测站上空的开阔性, 避免对GPS卫星信号接收带来影响。

\section{2 全天候观测}

GPS技术能够在任何地点和时间进行连续观测, 不受天气和环境的影 响, 且GPS技术的观测时间相对较短, 控制网下各个观测站的观测时间约
技术运用的质量, 避免因为操作问题而导致RTK技术运用的测量结果受到 影响。因此, 在市政工程测量中进行RTK技术运用时, 要把人才培养作为技 术应用的首要原则, 以保证市政工程测量中RTK技术运用的质量。市政工程 测量中RTK技术运用人才培养机制落实主要有两种方式: 一是专业技术人 员引进。通过对大学院院校高端人才进行引进, 为RTK技术在市政工程测量 中的应用提供保证。二是对现有工程测量人员进行技术培训, 保证其RTK 技术运用的专业性。通过培训机制落实, 要求具有RTK技术应用经验的专业 技术人员对市政工程单位现有的测量人员进行专业培训, 强化其RTK技术 应用能力。

\section{5 结论}

RTK技术在市政工程测量中运用是新时期提升测量工作作业效率和测 量精准性的必然途径, 是推动市政工程施工行业发展的重要举措。在进行
$30 \mathrm{~min}$, 一般不会超过 $40 \mathrm{~min}$, 在观测过程中使用快速静态定位法的情况下, 会缩短GPS测量技术的观测时间。

1.3 定位精度高

GPS测量技术的定位精度比较高, 一般双频GPS接收机的精度是 $5 \mathrm{~mm}+1$ $\times \mathrm{D}$, 与红外仪表的精度相似, 但在长距离定位中GPS定位精度比较优 越, GPS定位具有高精度、高准确性等特点。

\section{4 操作简单、便捷}

GPS测量技术的自动化程度比较高, GPS接收机呈现出操作简单化、体 积小型化等特点, 在实际观测过程中, 只需整平中天线, 在掌握天线高度后 打开电源, GPS技术能够自动接收测量数据和信息, 以获取被测点的三维坐 标, 为观测工作的顺利实施提供了很大便利。

\section{GPS 技术在测量工程中的应用}

在某测量工程中, 技术人员采集野外信息时应用了6台静态单频GPS接 收机, 其测量精度是 $5 \mathrm{~mm} \pm 1 \mathrm{ppm}$, 需要严格按照作业基本要求进行, 数据采 样率需要控制在 $30 \mathrm{~s}$ 之内, 时段长度在 $60 \mathrm{~min}$ 以上, 观测有效卫星数量大于 4 , 平均重复设站数大于 1.6 , 卫星截止高度大于 $15^{\circ}$ 。另外, 各个时段观测方 式都是测量天线高两次, 两次差需要控制在 $3 \mathrm{~mm}$ 以内, 天线高是测量平均值, 技术人员利用Ashtechsolutoons 2. 5 针对GPS观测数据进行基线解算, 确保 各个基线求出整周模糊度, 下文对GPS技术在工程控制测量中的应用进行 了分析。

2. 1 静态定位

技术人员可以在各个流动站中设置GPS接收机, 在实际观测过程中实 行静止观测方式, 针对太空卫星传输信号进行接收, 准确记录基准站的同 步数据, 以此为基础结算监测站一周的未知数、三维坐标, 在测量进度满足

RTK技术运用的过程中, 要保证技术应用的科学性, 为市政工程测量科学化 开展提供技术支撑。

[参考文献]

[1]张楠.探讨RTK技术在市政工程测量中的应用[J].城市建设理论研 究(电子版),2017,(19): 174+179.

[2]邹嘉.RTK测量技术在市政工程测量中的优化应用分析 [C]//川、渝、 滇、黔、桂煤炭学会2017年度学术年会(重庆部分)论文集,2017:159-161. [3]王伟.GPS-RTK技术在市政工程测绘中的应用 [J]. 建筑技术开 发,2017,44(1):96-97.

作者简介：

刘玉强(1981--), 男, 河北省承德市宽城县人, 满族, 本科, 测绘中级 工程师,研究方向：市政工程测量、不动产测绘专业。 